\title{
A REVIEW OF BLOOD SUBSTITUTES: EXAMINING THE HISTORY, CLINICAL TRIAL RESULTS, AND ETHICS OF HEMOGLOBIN-BASED OXYGEN CARRIERS
}

\author{
Jiin-Yu Chen, Michelle Scerbo, George Kramer
}

doi: $10.1590 / \mathbf{S 1 8 0 7 - 5 9 3 2 2 0 0 9 0 0 0 8 0 0 0 1 6}$

Chen JY, Scerbo M, Kramer G. A review of blood substitutes: examining the history, clinical trial results, and ethics of hemoglobin-based oxygen carriers. Clinics. 2009;64(8):803-13.

\begin{abstract}
The complications associated with acquiring and storing whole blood for transfusions have launched substantial efforts to develop a blood substitute. The history of these efforts involves a complicated mixture of science, ethics, and business. This review focuses on clinical trials of the three hemoglobin-based oxygen carriers (HBOC) that have progressed to Phase II or III clinical trials: HemAssist (Baxter; Deerfield, IL, US), PolyHeme (Northfield; Evanston, IL, US), and Hemopure (Biopure; Cambridge, MA, US). Published animal studies and clinical trials carried out in a perioperative setting have demonstrated that these products successfully transport and deliver oxygen, but all may induce hypertension and lead to unexpectedly low cardiac outputs. Overall, these studies suggest that HBOCs resulted in only modest blood saving during and after surgery, no improvement in mortality and an increased incidence of adverse reactions. To date, the results from these perioperative studies have not led to regulatory approval. All three companies instead chose to focus their efforts on large trials of trauma patients in the pre-hospital setting.

Baxter abandoned the development of HemAssist after a trial in the U.S. was prematurely halted when the first 100 patients showed significantly increased mortality rates as compared to patients treated with blood products. Northfield's PolyHeme trial demonstrated a non-significant trend towards increased mortality and a very modest reduction in the subsequent need for blood. The testing of Biopure's Hemopure for trauma patients has been halted for several years because of FDA concerns over trial design and study justification. Ethical concerns have also been raised regarding the design and implementation of all HBOC clinical trials.

Thus, the available evidence suggests that HemAssist, Polyheme, and Hemopure are associated with a significant level of cardiovascular dysfunction. The next generation of HBOCs remains under development.
\end{abstract}

KEYWORDS: Blood substitute; HBOC; PolyHeme; Hemopure; HemAssist.

\section{INTRODUCTION}

Blood transfusions are a life saving intervention, but also have inherent side effects and dangers. Blood donated in the U.S. today is remarkably safe because of the sensitive assays used to detect blood-borne diseases. Despite this, allogeneic blood transfusion still carries a risk of exposure to blood borne pathogens, such as viral hepatitis and HIV. Blood is screened with nucleic acid amplification testing, which has reduced the risk of HIV transmission through donated blood

Anesthesiology, University of Texas Medical Branch - Galveston/TX, USA Email: jichen1@utmb.edu

Tel: 14097723969

Received for publication on April 21, 2009

Accepted for publication on May 06, 2009 to approximately one in 1.9 million. ${ }^{1}$ Another complication that can occur with blood transfusions is inaccurate cross-matching, which ran result in antigen binding and subsequent agglutination. Although the incidence of fatal ABO-incompatible transfusions is less than one in 1.5 million transfusions, it remains the leading direct cause of deaths resulting from blood transfusion. ${ }^{2}$

However, the greatest risk of transfusions may be the alterations they induce in recipients' immunological function. Shortly after trauma resulting from accidents or major surgeries, an individual's immune system is upregulated. Thus, trauma itself, along with transfusions, can cause cytokine release, including systemic inflammatory response. ${ }^{3}$ However, as time elapses after trauma has occurred, a patient's immune function will become 
down-regulated and additional transfusions can further depress neutrophil activity and put the patient at risk of infection. Repeated blood transfusions can lead to serious complications, as the incidence of multiple organ failure (MOF) increases with the amount of blood transfused. ${ }^{4}$ This finding may result from a severe systemic inflammatory response caused by multiple blood transfusions.

Logistical and practical constraints may reduce blood availability and increase the cost of blood transfusions. Hospitals and blood banks often experience shortages of donated blood. Additionally, the ability to meet the need for blood in a mass casualty situation or in combat casualty care is often limited. Donated and stored red blood cells have a short stored shelf life (42 days) and must be stored in a refrigerated environment. Stored blood also loses 2,3-diphosphoglycerate (2,3-DPG) as time progresses, increasing its oxygen affinity and impairing oxygen unloading capacity in tissues. Thus, the biological limitations, side effects and logistical constraints of blood transfusions underscore the importance of developing a viable blood substitute.

For more than 100 years researchers have pursued the "Holy Grail" of trauma medicine: a blood substitute. The ideal blood substitute would retain all the functions of blood and none of the transfusion problems associated with blood. The term "blood substitute" does not accurately describe the current candidate products because they typically have only two limited functions: carrying and delivering oxygen and augmenting blood volume. Although no single product can yet imitate all the properties of blood, substantial progress has been made, especially in the development of hemoglobin based oxygen carriers (HBOCs). Although some products have come close, no HBOC has yet been approved for clinical use in the U.S. or Europe. This review focuses on the history and clinical trial results of the three HBOCs that have progressed to Phase II or III clinical trials: HemAssist, PolyHeme, and Hemopure.

\section{Early History}

Research exploring alternatives to blood began approximately 150 years ago. Searching for a blood substitute, T. Gaillard Thomas ${ }^{5}$ posited that intravenous infusion of cow's milk, a process he termed "lacteal injections," might have the potential to save lives. He justified his position by enumerating chemical similarities between lymphatic chyle and milk, emphasizing that both are fats that are emulsified in fluid. Thomas presented three case studies of moribund patients into whom he injected about 8 ounces of fresh cow's milk. In these case studies, one patient survived and two died. He attributed their deaths to other complications unrelated to the lacteal injections and claimed the injections were safe provided that fresh milk was used.

Despite Thomas's claims, the development of blood substitutes logically turned to creating hemoglobin solutions, which were first clinically tested in the early $20^{\text {th }}$ century. Hemoglobin's oxygen carrying characteristics made it the logical choice for blood substitutes, but its uses came with unexpected consequences. Amberson et al. performed experiments in cats in which they completely replaced the animals' blood with cell-free hemoglobin in lactated Ringer's solution and showed that the solution could sustain life. ${ }^{6}$ However, the benefits were short-lived and the treatment caused significant renal damage. Despite these observations, the group performed clinical trials using a product containing hemoglobin in lactated Ringer's solution, which unfortunately produced significant renal dysfunction in 5 of 14 patients. ${ }^{7}$ Amberson et al. abandoned their studies and concluded that hemoglobin solutions required further development because of the associated renal toxicity and vascular hypertension. In the 1950s, the U.S. Navy treated 47 anemic and febrile sailors with one or more infusions of free hemoglobin solutions. ${ }^{8}$ Seventeen sailors became hypertensive and 12 out of 52 infusions led towards signs of renal problems. The remaining sailors who did not have renal problems experienced other untoward side effects. Renal toxicity seemed to be caused by obstruction of renal tubules as a result of hemoglobin and red cell stroma deposition, impaired renal function linked with heme pigment deposition, and decreased renal blood flow due to hemoglobin-induced vasoconstriction. ${ }^{8}$

Because of the evidence that hemoglobin-based blood substitutes were associated with renal toxicity, interest in these solutions waned and several years passed before useable stroma free hemoglobin solutions were developed. Ultra-purification techniques that allowed for the removal of stroma and other cellular debris from these compounds largely solved the problem of renal toxicity. However, new problems emerged. Native tetrameric hemoglobin, when removed from the red cell, breaks down into dimers, which are rapidly cleared by glomerular filtration, resulting in a short vascular half-life. Furthermore, free hemoglobin has reduced contact with phosphates, causing the $\mathrm{P}_{50}$ curve to shift to the left, resulting in hemoglobin with a high oxygen affinity and limited oxygen unloading.

To address these limitations, a variety of approaches were used to molecularly stabilize and chemically modify hemoglobin. In the late 1960s, researchers for the U.S. Army offered a new and promising hemoglobin solution. Bunn and Jandl ${ }^{9}$ crosslinked hemoglobin with bis (N-maleimidomethyl) ether (BME), prolonging its intravascular retention. Crosslinking reduced the hemoglobin 
molecule's tendency to form dimers, thus decreasing its renal filtration and clearance.

Other investigators produced hemoglobin that had been chemically modified at the 2,3-DPG site, the amino terminal group, or internally ${ }^{10,11}$ in an attempt to prevent hemoglobin from disassociating into the $\alpha \beta$ dimers and as a means of restoring the $\mathrm{P}_{50}$ to near-normal levels. Using a different approach, Bonsen et al. ${ }^{12}$ produced a hemoglobin that was polymerized with glutaraldehyde, which prolonged its intravascular retention. Another modification approach involved the attachment of hemoglobin to a larger molecule, which caused it to stay within the vascular system for a longer period of time than non-modified hemogobin. In one study, hemoglobin coupled to dextran ${ }^{13}$ showed to support life in dogs and cats in the absence of red blood cells. ${ }^{14}$

Out of these and other suggested chemically modified hemoglobins, several products progressed to human studies and limited testing in human patients. However, only three advanced to Phase II and III trials in peer-reviewed journals. Our review focuses on these three products: HemAssist (Baxter), PolyHeme (Northfield), and Hemopure (Biopure).

Although other HBOCs have been studied in clinical trials, the results have been under-reported to date. These products include Hemosol's Hemolink and Somatogen's Optro. Development of both products was reportedly halted due to increased rates of cardiac arrest. Both companies have ceased operations. In the following sections, we review the research and development process and results from the key clinical trials of HemAssist, PolyHeme, and Hemopure.

\section{Methods of Selection}

We sought to identify all Phase II and III clinical trials involving HemAssist, PolyHeme and Hemopure by searching Medline using the keywords for the commercial and research names of these products (specifically, we used the terms "HemAssist," "DCLHb," "PolyHeme," "SFH-P," "Hemopure," and "HBOC-201"). Additionally, we also reviewed company press releases to find information regarding recent trials and company efforts. We omitted Phase I clinical trials in healthy volunteers, case reports, trials with no control group, trials with fewer than 40 participants, and interim studies that were subsequently published in full. We extracted data regarding patient populations, HBOC dosage, the control group dosage and key results for all included studies.

\section{Corporate History and Initial Research and Development}

DCLHb/HemAssist (Baxter): In the 1980s, researchers at the Letterman Army Institute of Research (LAIR) began working on a blood substitute similar to the previously studied solutions containing glutaraldehyde-treated hemoglobin. These scientists eventually created diaspirin cross-linked hemoglobin (DCHb). In order to move their product to the larger scale for clinical trial lots, competitive bids were solicited from private industry and DCLHb was eventually licensed to Baxter Healthcare in 1985.

The formulation was called $\alpha \alpha-\mathrm{Hb}$ by the U.S. Army and DCLHb or HemAssist by Baxter. The source of hemoglobin was outdated human red blood cells that were pooled, washed, lysed and filtered. The product was then deoxygenated, crosslinked with bis(3,5-dibromosalicyl) fumarate, and reoxygenated. One unit of Baxter's DCLHb was made with $25 \mathrm{~g}$ hemoglobin in $250 \mathrm{ml}$, resulting in a concentration of $10 \mathrm{~g} / \mathrm{dL}$. DCLHb solutions exhibited a $\mathrm{P}_{50}$ of $32 \mathrm{mmHg}$, a colloid osmotic pressure (COP) of $42 \mathrm{mmHg}$ and a methemoglobin content of $<5 \% .{ }^{15}$ It also

Table 1 - Properties of hemoglobin based oxygen carriers

\begin{tabular}{|c|c|c|c|}
\hline \multicolumn{4}{|c|}{ Properties of Hemoglobin Based Oxygen Carriers } \\
\hline \multirow[b]{2}{*}{ Characteristics } & \multicolumn{3}{|c|}{ Products } \\
\hline & $\begin{array}{l}\text { DCLHb } \\
(\text { Baxter })^{15}\end{array}$ & $\begin{array}{c}\text { SFH-P } \\
\text { (Northfield) }^{21,23}\end{array}$ & $\begin{array}{l}\text { HBOC-201 } \\
\text { (Biopure) }^{26}\end{array}$ \\
\hline Solution Concentration $(\mathrm{g} / \mathrm{dL})$ & 10 & 10 & $12-14$ \\
\hline $\mathrm{P}_{50}(\mathrm{mmHg})$ & 32 & $20-22$ & 40 \\
\hline $\mathrm{COP}(\mathrm{mmHg})$ & 42 & $20-25$ & 25 \\
\hline Methemoglobin (\%) & $<5$ & $<5$ & $<10$ \\
\hline Average Weight (kDa) & 64 & 150 & 250 \\
\hline Viscosity (cp) & 1.2 & $1.9-2.2$ & 1.3 \\
\hline In vivo Half-life (hrs) & $6-12$ & 24 & 19 \\
\hline Shelf-life (yrs) & $1+$ & $1+$ & 3 \\
\hline Storage Temperature $\left({ }^{\circ} \mathrm{C}\right)$ & $<5$ & $4-8$ & $2-30$ \\
\hline
\end{tabular}


exhibits a long shelf life when stored in a freezer. Table 1 lists additional characteristics of DCLHb.

Conflicts arose between the LAIR group and Baxter over direction of research and development and the two groups severed ties. Baxter Healthcare continued to develop the product, which they called HemAssist, and aggressively pursued animal studies and clinical trials. The U.S. Army continued to perform pre-clinical animal work with the $\alpha \alpha-\mathrm{Hb}$ formulation. A July 2007 Medline search using keywords "DCLHb" or "HemAssist" returned 29 clinical, 114 animal and 8 in vitro studies. Overall, the results of the U.S. Army's sponsored research were discouraging, while Baxter's animal research suggested that HemAssist might have clinical efficiency. Baxter's HemAssist then advanced through a series of Phase I clinical trials and became the first HBOC to advance to Phase II and III clinical trials.

No published study documented a difference between the U.S. Army's $\alpha \alpha-\mathrm{Hb}$ and Baxter's final HemAssist product. Baxter performed over a hundred animal studies and the U.S. Army published several studies, with some reports indicating that the product caused vasoconstriction. The U.S. Army sponsored studies that suggested the vasoconstriction was a severe limitation, but the Baxter studies found that HemAssist improved tissue oxygenation and hypothesized that clinical benefits might result from the vasoconstriction. ${ }^{16}$ We discuss major clinical trials using DCLHb in the next section, Key Clinical Trials.

SFH-P/PolyHeme (Northfield): Northfield Laboratories, located in Evanston, Illinois, was not established until 1985, although the developers of poly stroma-free hemoglobin (SFH-P, PolyHeme) began developing the formulation in 1969 in conjunction with the U.S. Army. ${ }^{17}$ The U.S. Army funded initial studies and the company went public in 1994. In contrast with Baxter, Northfield published little data from animal studies and performed only a few clinical trials. A July 2007 Medline search using keywords "SFH-P" or "PolyHeme" returned 10 clinical trials, 8 animal and 3 in vitro studies. However, on closer examination of the references, only five studies presented clinical data. These studies provided sparse data regarding the physiological occurrences during infusion, but focused instead on reductions in the requirement for red blood cell (RBC) transfusions as a result of product usage. The only published animal studies on PolyHeme that included significant physiologic data were performed recently in independent experimental assessments of PolyHeme performed by the U.S. Army. ${ }^{18,19}$ Thus the scientific community had the opportunity to examine data from animal studies only after several clinical studies were performed.

The physiological effects of PolyHeme were largely unknown to the research community until these recent studies. Northfield reported that PolyHeme was devoid of the vasoconstrictive effects that was a noted side effect of the other HBOCs. ${ }^{20}$ Northfield reasoned that SFH-P did not result in the vasoconstrictive effects because the polymerized hemoglobin was too large to extravasate into the interstitial space, thus resulting in only limited binding of nitric oxide, which has vasodialatory effects. ${ }^{21}$ Deoxyhemoglobin has a high affinity for nitric oxide and thus readily binds it, subsequently depleting the amount of nitric oxide in the blood vessel and causing hypertension. ${ }^{22}$ In contrast to Northfield's findings, both Baxter and Biopure reported vasoconstriction when testing variations of polymerized hemoglobin that were similar to SFH-P (Burhop K 2003, oral communication). Northfield's clinical studies revealed only mild increases in systemic blood pressure, but did not include acute data on cardiac output, pulmonary pressures, calculated vascular resistances. Studies performed in independent U.S. Army laboratories demonstrated that PolyHeme exhibited vasoconstrictive properties and conferred no survival value in swine and rat models of hemorrhage. ${ }^{18,19}$

SFH-P is produced by crosslinking the stroma-free hemoglobin from outdated RBCs with glutaraldehyde and then pyridoxylating it. The product has a $\mathrm{P}_{50}$ of 20-22 mmHg (compared to a normal $\mathrm{RBC}$, which exhibits a $\mathrm{P}_{50}$ of $26 \mathrm{mmHg}$ ). To obtain a COP that is near the normal value, the hemoglobin is polymerized with glutaraldehyde and all unreacted tetramer is then removed..$^{21}$ One unit of SFH-P consists of $50 \mathrm{~g}$ of hemoglobin in $500 \mathrm{~mL}$ electrolyte solution, which is equivalent to less than $50 \%$ of the hemoglobin content in a typical unit of packed red blood cells (PRBCs). At $10 \mathrm{~g} / \mathrm{dL}$, the final product has a COP of 20-25 mmHg. A molecule of SFH-P has an average weight of $150 \mathrm{kDa}$ (range: 64 and $400 \mathrm{kDa}$ ). The viscosity is double that of saline. Methemoglobin accounts for less than $5 \%$ of the final product and the product is stable for at least a year, when stored at $4-8^{\circ} \mathrm{C} .{ }^{21}$ Additional characteristics of SHF-P are included in Table 1.

In 1998, results were published from the first clinical trial to investigate SFH-P $\mathrm{P}^{23}$ and, since then, Northfield has completed two Phase II and one Phase III trial to assess SFH-P. Northfield completed enrollment for PolyHeme's Phase III trials in July 2006 and reported results from those trials in late 2006 and mid 2007..$^{24,25}$ These results are discussed in the next section.

HBOC-201/Hemopure (Biopure): Biopure, located in Cambridge, MA, developed Hemopure (hemoglobin glutamer-250, HBOC-201), which is produced from highly purified bovine hemoglobin. HBOC-201 is Hemopure's third-generation product; the company had previously developed two other solutions that were explored through 
various pharmacological studies. ${ }^{26}$ The first generation solution, Hemopure 1 Solution (H1S, Polymerized Bovine Hemoglobin), composed of 50\% tetrameric hemoglobin and was used in a Phase I safety study, however its development was abandoned because patients experienced unacceptable gastrointestinal problems. ${ }^{27}$ Hemopure 2 Solution (HBOC301, Oxyglobin) was Biopure's next-generation product. Its properties are similar to those of HBOC-201, with a lower average molecular weight. ${ }^{26}$ In 1998, Oxyglobin was approved for veterinary use, with a primary indication of managing canine anemia. Oxyglobin continues to receive significant enthusiasm from many veterinarians. ${ }^{28}$

HBOC-201 is Hemopure's current product for human use and has undergone both animal studies and extensive clinical testing. A July 2007 Medline search using keywords "HBOC-201" or "Hemopure" returned 21 clinical, 44 animal and 15 in vitro publications. HBOC-201 is derived from bovine hemoglobin, polymerized with glutaraldehyde. The solution is ultrapurified, which removes or inactivates potential contaminants such as cellular stroma, infectious agents and endotoxins. ${ }^{26}$ The final product's hemoglobin concentration is $13 \mathrm{~g} / \mathrm{dL}$, which is the highest concentration of the three formulations. HBOC-201's $\mathrm{P}_{50}$ is $40 \mathrm{mmHg}$, resulting in a lower oxygen affinity than native hemoglobin and the lowest $\mathrm{P}_{50}$ of the three solutions. Additionally it exhibits the highest methemoglobin percentage and the heaviest average weight of the three products. It also has the longest shelf life and can be stored at the widest range of temperatures. ${ }^{26}$ Additional characteristics of HBOC-201 are included in Table 1.

\section{Key Clinical Trials}

Tables 2, 3, and 4 summarize the key Phase II and III trials for HemAssist, PolyHeme, and Hemopure. Several smaller trials are not listed or discussed because they are either interim studies or have a very small patient population. We list the primary conclusions from the published studies and we only report physiologic effects that were statistically significant. We report all results on blood sparing and any other major clinical finding as reported by the authors, regardless of their statistical significance.

DCLHb/HemAssist (Baxter): HemAssist showed both promise and problems when studied in over 20 perioperative

Table 2 - HemAssist clinical trials

\begin{tabular}{|c|c|c|c|c|}
\hline Patient Population & Control Dosage & HBOC Dosage & Physiologic Effects & Treatment Effects \\
\hline Surgical Patients ${ }^{15}$ & $\begin{array}{l}\text { Allogeneic PRBC transfusion } \\
(\mathrm{n}=105), \mathrm{Up} \text { to } 3 \mathrm{U}^{\mathrm{a}}\end{array}$ & $(\mathrm{n}=104), \mathrm{Up}$ to $3 \mathrm{U}$ & $\begin{array}{l}\uparrow \text { MAP SVR, Mean PAP, PVR } \\
\downarrow \text { CO, HR }\end{array}$ & $\downarrow$ Day 1 PRBC use* \\
\hline $\begin{array}{l}\text { Stroke } \\
\text { Patients }{ }^{29}\end{array}$ & $\begin{array}{l}\text { Saline }(\mathrm{n}=45), \\
25-100 \mathrm{mg} / \mathrm{kg}\end{array}$ & $(\mathrm{n}=40), 25-100 \mathrm{mg} / \mathrm{kg}$ & $\uparrow$ MAP & $\begin{array}{l}\uparrow \text { jaundice* }^{*} \text { hemoglobinuria* } \\
\downarrow \text { Three month outcome }\end{array}$ \\
\hline Surgical Patients ${ }^{30}$ & $\begin{array}{l}\text { Allogeneic PRBC transfusion } \\
(\mathrm{n}=84), \mathrm{Up} \text { to } 3 \mathrm{U}\end{array}$ & $(\mathrm{n}=89), \mathrm{Up}$ to $3 \mathrm{U}$ & None reported & $\begin{array}{l}\uparrow \text { jaundice }{ }^{*} \text {, urinary problems } \\
\text { pancreatitis } \\
\downarrow \text { PRBC use through Day } 7^{*} \\
\text { Terminated early }\end{array}$ \\
\hline Trauma Patients ${ }^{32}$ & $\begin{array}{l}\text { Normal Saline }(\mathrm{n}=46), \\
500-1000 \mathrm{~mL}\end{array}$ & $\begin{array}{l}(\mathrm{n}=52) \\
2-4 \mathrm{U}\end{array}$ & None reported & $\begin{array}{l}\uparrow \text { mortality* }^{*} \\
\text { Terminated early }\end{array}$ \\
\hline Trauma Patients ${ }^{34}$ & $\begin{array}{l}\text { Standard hemorrhagic shock } \\
\text { resuscitation fluids }^{\mathrm{b}}(\mathrm{n}=62), \text { PRN }\end{array}$ & $(\mathrm{n}=53), \mathrm{Up}$ to $2 \mathrm{U}$ & None reported & $\begin{array}{l}\downarrow \text { PRBC use } \\
\text { Terminated early }\end{array}$ \\
\hline
\end{tabular}

${ }^{\mathrm{a}} 1 \mathrm{U}=250 \mathrm{~mL} .{ }^{\mathrm{b}}$ Standard hemorrhagic shock resuscitation fluids included volume expanders, crystalloids, colloids, plasma, blood, and vasopressors $*=\mathrm{p}<0.05$; all physiologic effects were reported as statistically significant per authors' criteria. MAP $=$ mean arterial pressure, $\mathrm{SVR}=$ systemic vascular resistance, $\mathrm{PAP}=$ pulmonary arterial pressure, $\mathrm{PVR}=$ pulmonary vascular resistance, $\mathrm{PRBC}=$ packed red blood cells

Table 3 - PolyHeme clinical trials

\begin{tabular}{|c|c|c|c|c|}
\hline Patient Population & Control Dosage & HBOC Dosage & Physiologic Effects & Treatment Effects \\
\hline Surgical/Trauma Patients ${ }^{23}$ & $\begin{array}{l}\text { Allogeneic PRBC transfusion } \\
(\mathrm{n}=23), \text { PRN }\end{array}$ & $(\mathrm{n}=21), \mathrm{Up}$ to $6 \mathrm{U}^{\mathrm{a}}$ & None reported & Maintained total $[\mathrm{Hb}]$, but not $\mathrm{RBC}[\mathrm{Hb}]^{*}$ \\
\hline Trauma Patients ${ }^{35}$ & $\begin{array}{l}\text { Historical controls, declined } \\
\text { transfusions }\end{array}$ & $(\mathrm{n}=171), \mathrm{Up}$ to $20 \mathrm{U}$ & None reported & Maintained total $[\mathrm{Hb}]$, but not $\mathrm{RBC}[\mathrm{Hb}]$ \\
\hline Trauma Patients ${ }^{25}$ & $\begin{array}{l}\text { Standard hemorrhagic shock } \\
\text { resuscitation fluids }(\mathrm{n}=307), \text { PRN }\end{array}$ & $(n=279), U p$ to $6 U$ & None reported & $\begin{array}{l}\uparrow \text { cardiac adverse effects } \\
\downarrow \mathrm{PRBC} \text { use }\end{array}$ \\
\hline
\end{tabular}

${ }^{\mathrm{a}} 1 \mathrm{U}=250 \mathrm{~mL} ;{ }^{\mathrm{b}}$ Standard hemorrhagic shock resuscitation fluids included volume expanders, crystalloids, colloids, plasma, blood, and vasopressors

$*=\mathrm{p}<0.05 . \mathrm{Hb}=$ hemoglobin, $\mathrm{RBC}=$ red blood cells, $\mathrm{PRBC}=$ packed red blood cells 
Table 4 - Hemopure clinical trials

\begin{tabular}{|c|c|c|c|c|}
\hline Patient Population & Control Dosage & HBOC Dosage & Physiologic Effects & Treatment Effect \\
\hline Surgical Patients ${ }^{38}$ & $\begin{array}{l}\text { Allogeneic PRBC transfusion } \\
(\mathrm{n}=24), \text { PRN }\end{array}$ & $\begin{array}{l}(\mathrm{n}=40), 60 \mathrm{~g} \text {, option of } 3 \text { more } \\
\text { doses of } 30 \mathrm{~g}\end{array}$ & $\begin{array}{l}\uparrow \text { MAP, serum urea }\left[\mathrm{N}_{2}\right] \text {, Bicar- } \\
\text { bonate, BE, plasma }[\mathrm{Hb}] \\
\downarrow \text { Hct }\end{array}$ & $\begin{array}{l}\downarrow \text { PRBC use in } 27 \% \text { of } \\
\text { patients }\end{array}$ \\
\hline Surgical Patients ${ }^{39}$ & $\begin{array}{l}\text { Allogeneic PRBC transfusion } \\
(\mathrm{n}=48), \text { PRN }\end{array}$ & $\begin{array}{l}(\mathrm{n}=50), 60 \mathrm{~g}, \text { option of } 3 \text { more } \\
\text { doses of } 30 \mathrm{~g}\end{array}$ & $\begin{array}{l}\uparrow \text { MAP, Mean PAP, arterial } \mathrm{O}_{2} \\
\downarrow \mathrm{CI}, \mathrm{SpO}_{2}\end{array}$ & $\begin{array}{l}\uparrow \mathrm{O}_{2} \text { extraction* } \\
\downarrow \text { PRBC use }\end{array}$ \\
\hline Surgical Patients ${ }^{40}$ & $\begin{array}{l}\mathrm{LR} \\
(\mathrm{n}=26), 849 \mathrm{~mL}\end{array}$ & $\begin{array}{l}(\mathrm{n}=55), \\
0.6 \mathrm{~g} / \mathrm{kg}-2.5 \mathrm{~g} / \mathrm{kg}\end{array}$ & $\uparrow$ plasma $\mathrm{Hb}$ & $\begin{array}{l}\text { Intraoperative use of } \\
\text { HBOC well tolerated }\end{array}$ \\
\hline Surgical Patients ${ }^{42}$ & $\begin{array}{l}\text { Allogeneic PRBC transfusion } \\
(\mathrm{n}=338), \text { PRN }\end{array}$ & $(\mathrm{n}=350), 65 \mathrm{~g}$, up to $325 \mathrm{~g}$ & $\uparrow$ total $[\mathrm{Hb}], \mathrm{Hct}$ & $\begin{array}{l}\uparrow \text { cardiac adverse effects" } \\
\downarrow \text { PRBC } \text { use }^{*}\end{array}$ \\
\hline
\end{tabular}

${ }^{*}=\mathrm{p}<0.05$; all physiologic effects reported as statistically significant per the authors' criteria, LR= lactated Ringer's solution, RBC $=$ red blood cells, $\mathrm{PRBC}=$ packed red blood cells, $\mathrm{MAP}=$ mean arterial pressure, $\mathrm{BE}=$ base excess, $\mathrm{Hb}=$ hemoglobin, $\mathrm{Hct}=$ hematocrit, $\mathrm{PAP}=$ pulmonary arterial pressure, $\mathrm{CI}=$ cardiac index

and intensive care unit (ICU) setting. The key clinical trials that evaluated HemAssist are listed in Table 2. One study compared HemAssist to PRBC in 209 postoperative cardiac bypass surgery patients. ${ }^{15}$ The patients received up to three $250 \mathrm{~mL}$ infusions of HemAssist or PRBCs. The HemAssist group exhibited increased systemic and pulmonary vascular resistances and pressures compared with the control group. Mortality was similar in both groups. About 1 in 5, or $19 \%$, of the patients in the HemAssist completely avoided exposure to PRBCs. Although patients in the HemAssist group received significantly less PRBC units on day 0 and day 1 post surgery, a significant reduction in the total number of PRBCs administered was not observed because the HemAssist patients did not cumulatively receive less blood products over the course of the study.

A study of 85 patients who had experienced acute ischemic stroke evaluated the use of HemAssist within 18 hours of the onset of symptoms. Normal saline was used as the control. ${ }^{29}$ The researchers administered HemAssist in 12 doses of 25,50 or $100 \mathrm{mg} / \mathrm{kg}$ over 72 hours, resulting in an increase in mean arterial pressure from $113 \pm 14 \mathrm{mmHg}$ to $134 \pm 20 \mathrm{mmHg}$, versus no increase in saline controls. The patients were evaluated at three months. Severe stroke at baseline and treatment with DCLHb showed to be independent predictors of an unfavorable outcome, based upon the Rankin scale. Thirty-four (85\%) patients in the HemAssist group had an unfavorable outcome, as opposed to $23(51 \%)$ in the control groups.

A multicenter trial compared HemAssist against PRBC in 181 patients undergoing elective surgery. ${ }^{30}$ Patients received up to three $250 \mathrm{~mL}$ of either HemAssist or PRBCs. Blood sparing was possible in $23 \%$ of the HemAssist patients. However, the HemAssist-treated patients were also more likely to suffer from adverse effects. Because of safety concerns, the study was terminated early.

In 1997, Baxter launched their final, pivotal study, testing HemAssist on patients in ambulance and emergency departments (ED) in both the United States and Europe. The first trial conducted under the FDA's exception from informed consent for emergency research (21 CFR 50.24). For the U.S. trial, the investigators planned to enroll 850 patients in the study from 35 trauma centers across the U.S. to determine whether the solution resulted in a decrease in the 28 day mortality. ${ }^{31}$ The study was designed as a randomized, single blinded efficacy trial of patients with traumatic hemorrhagic shock and unstable vitals. Patients were to receive either $500 \mathrm{~mL}$ of HemAssist or normal saline. ${ }^{32}$ In 1998, the trial's independent data monitoring committee performed an interim data review after approximately 100 patients had been enrolled..$^{33}$ HemAssist was found to be significantly less effective than the standard of care and the study was terminated. Of the 52 patients infused with HemAssist, 24 (46\%) died, whereas only 8 (17\%) of the 46 saline patients died. The cause for the increased mortality could not be established from that data. However, researchers speculated that it was a result of the known vasopressor effects of hemoglobin solutions.

Baxter had also initiated a separate study in Europe around that time. A study involving 121 patients suffering from severe hemorrhagic shock examined the use of HemAssist in reducing MOF from tissue hypoxia. ${ }^{34}$ The groups received either up to $1000 \mathrm{~mL}$ of $10 \%$ HemAssist solution or the study center's standard therapy. However, the study was prematurely terminated because HemAssist did not significantly reduce rates of organ failure and because researchers could not offset other concerns raised about HemAssist's safety record during the U.S. trial. Because of these problems, commercial production of HemAssist ceased. Baxter evaluated recombinant hemoglobin formulations for a several more years and eventually terminated its HBOC program.

SFH-P/PolyHeme (Northfield): The first prospective, 
randomized study using PolyHeme ${ }^{23}$ evaluated its safety and therapeutic benefits compared to allogeneic red blood transfusion. Forty-four trauma patients were randomized, with 23 receiving PRBC and 21 receiving up to 6 units of PolyHeme ( $4.4 \pm 2.0$ units). Adverse events or safety issues were not reported for PolyHeme, suggesting it was welltolerated in this setting. PolyHeme maintained hemoglobin concentration and reduced the need for allogeneic blood by approximately 3.5 units.

Another large study compared 171 trauma patients who received PolyHeme during surgery to a historical control group of 300 patients who refused red cells for religious reasons..$^{35}$ The PolyHeme patients received up to 20 units and the study compared their 30 day mortality rates against the control. PolyHeme maintained total hemoglobin concentration in the 7 to $10 \mathrm{~g} / \mathrm{dL}$ range and the mortality rate in this group was $25 \%$, compared with a mortality rate of $65 \%$ in the historical control group. However, the U.S. Food and Drug Administration (FDA) made it clear that they would not accept historical control data as a Phase III clinical trial. A large multicenter, pre-hospital/emergency department study of PolyHeme was subsequently launched 2003.

In December 2006, Northfield announced in a press release it had completed enrollment in its Phase III clinical trial. At the same time, the company released preliminary data. ${ }^{24}$ Northfield reported more detailed results of the study in May 2007. ${ }^{25}$ The study included 586 patients with traumatic hemorrhagic shock, of whom 279 received PolyHeme and 307 received the hospital's standard of care. Thirty-one $(11.1 \%)$ of the PolyHeme patients died, while 28 (9.1\%) of the control patients died by the time the Day 30 mortality analysis was performed. In the PolyHeme group, $41 \%$ of the patients received additional PRBC transfusions, while $51 \%$ in the control group received additional blood. With regard to other safety data, $93 \%$ of the patients in the PolyHeme group and $88 \%$ of the patients in the control group experienced adverse effects, which largely consisted of anemia, fever, and electrolyte imbalance. In May 2009, the FDA refused to approve PolyHeme and in June 2009, Northfield filed for bankruptcy under the Chapter 11 Bankruptcy Code.

HBOC-201/Hemopure (Biopure): Key trials for Biopure are listed in Table 4. An early clinical study with Hemopure patients undergoing elective abdominal surgery illustrated a key physiologic function of HBOCs. ${ }^{36}$ The study examined Hemopure's effect on hemodynamics and oxygen transport. The patients received either $3 \mathrm{~mL} / \mathrm{kg}$ of Hemopure or $6 \%$ hydroxyethyl starch (HES) over 30 minutes and invasive arterial pressures, blood gases and cardiac index, vascular resistance, oxygen delivery, oxygen consumption, and oxygen extraction were monitored. Because of the reported increase in mean arterial pressure and systemic vascular resistance, as well as the notable decrease in cardiac index, the authors concluded that Hemopure impaired oxygen delivery because it induced a reduction in cardiac output. Similar results (impaired cardiac output despite the expected volume expansion) have also been reported for HemAssist and PolyHeme. ${ }^{37,19}$

Another intraoperative study evaluated 72 patients undergoing infrarenal aortic reconstruction, randomized in a 2 to 1 ratio to receive either Hemopure or red blood cell transfusions. ${ }^{38}$ Patients in the Hemopure group received $60 \mathrm{~g}$ of Hemopure as an initial transfusion, with up to 3 additional doses (30 g each) administered within 96 hours at the discretion of the treating physician. Hemopure eliminated the need for additional PRBC infusions in $27 \%$ of the treated patients but did not reduce the mean PRBC requirement of the patients who received it. It also caused a 15\% increase in mean arterial pressure.

A randomized, double-blind trial of Hemopure evaluated its efficacy as an alternative to red blood cell transfusion. ${ }^{39}$ The study included 98 patients undergoing cardiac surgery, who were randomly assigned to receive Hemopure or red blood cells for the first three postoperative transfusions. The Hemopure patients received $60 \mathrm{~g}$ of Hemopure in $500 \mathrm{~mL}$ for the initial transfusion and up to two additional infusions of $30 \mathrm{~g}$ in $250 \mathrm{~mL}$ over the next 72 hours. Although Hemopure lowered cardiac index, it eliminated any additional RBC transfusions in $34 \%$ of the patients who received it and it appeared to maintain oxygen transport.

In a randomized, single-blinded trial, the tolerability of a single dose of Hemopure was evaluated. ${ }^{40}$ The study included 81 surgical patients, who were randomized to receive either lactated Ringer's solution or a single infusion of Hemopure, both in doses of $0.6,0.9,1.2,1.5,2.0$ or $2.5 \mathrm{~mL} / \mathrm{kg}$. After evaluating Hemopure's effects on blood chemistry, hemoglobin concentration, methemoglobin concentration, urine output and pressure, the authors concluded that Hemopure was generally well-tolerated. However patients' blood pressures were slightly, but consistently, higher in the Hemopure group.

In December 2006, the FDA denied Biopure's application to study Hemopure in a Phase III trauma trial and recommended it undergo a pre-hospital Phase II study to evaluate its safety and efficacy in a study with a smaller patient population. ${ }^{41}$ Biopure recently published the results of their Phase III study evaluating Hemopure's ability to reduce or eliminate perioperative transfusion in orthopedic surgical patients. ${ }^{42}$ The study included 688 patients randomized to receive either Hemopure or PRBCs. The Hemopure patients received up to $325 \mathrm{~g}$ of Hemopure in $2,500 \mathrm{~mL}$ over a maximum of six days. Any additional blood 
requirements were met with PRBCs. The control group was administered PRBCs as needed. Hemopure reduced the need for additional blood transfusions in 59\% of the patients. However, the rate of adverse effects in the Hemopure group was significantly higher.

Although the FDA has not approved Hemopure, South Africa's Medicine Control Council issued its approval of the product in April 2001 for use in acutely anemic patients. ${ }^{43}$ This is particularly important because of the continuing HIV problem in South Africa. An HBOC can provide a safe transfusion alternative to donated blood, which may be infected with HIV.

\section{Ethical Issues Regarding HBOC Clinical Trials}

Perhaps because of the ambiguous results that resulted from the perioperative and ICU trials, all three companies elected to perform their Phase III trials in the pre-hospital trauma setting. They chose to do this because blood is not available during the pre-hospital period and therefore the investigators thought the rapid delivery of HBOCs may have the greatest impact on survival in this setting. The rationale for the setting was the potential that these HBOCs could potentially save more lives than were lost in the emergent trauma setting and that they could significantly reduce the number of transfusions required by patients. The PolyHeme trial was designed as a superiority/non-inferiority study, which aimed to demonstrate that PolyHeme was at least as effective as or possibly better than standard treatment. The FDA considers non-inferiority trials to be an acceptable study design and an acceptable marketing base for companies.

The recently completed Northfield trial showed that mortality was not significantly different between groups, despite a 22\% higher mortality rate with PolyHeme (11.1\%) versus the control group $(9.1 \%) .{ }^{25}$ The requirement for autologous blood was reduced from $51 \%$ to $41 \%$, in the control group and the PolyHeme group respectively.

If approved, a safe HBOC could change the way transfusion medicine is practiced and possibly reduce the morbidity and mortality of major surgical procedures and trauma. HBOCs have the potential to reduce the incidence of inflammatory effects that result from trauma and transfusions, as well as preventing other problems associated with transfusions. However, trials to evaluate HBOCs have impacted the healthcare community at the junction where clinical practices and societal ethics meet. For the Phase III trial that completed enrollment in December 2006, PolyHeme enrolled its patients under a rule established by the FDA in 1996, which waives informed consent in life-threatening conditions that must be handled quickly and when no better alternative is available. ${ }^{44}$ The PolyHeme trial enlisted the 32 Level 1 Trauma centers in 18 states and patients in hemorrhagic shock received either the hospital's normal standard of treatment or PolyHeme. ${ }^{24}$ The study design produced several problems. ${ }^{45}$ The waived informed consent rule that Northfield used to enroll patients concerned many ethicists and community leaders. Investigators were required to educate their communities about the trial, through a variety of means. People within the communities could then decide to "opt out" of the trial by wearing colored bracelets, indicating they did not want to participate in the study if they were subsequently injured and unable to give consent. Educating the public about the study was difficult for a variety of reasons, such as limited budgets and lack of guidelines for informing the public about the study.

Another ethical criticism of the study was aimed at the study design. Patients in the PolyHeme group received their initial dose while in the ambulance, on the way to the hospital, whereas the control subjects were given a crystalloid solution. However, once inside the ED, the control patients were given blood transfusions, while the PolyHeme patients continued to receive the test solution for the next 12 hours instead of blood. The waived informed consent rule stipulated that in order for the rule to be used, "available treatments... [must be] unproven or unsatisfactory." ${ }^{44}$ The study complied with this provision while PolyHeme subjects were in the ambulance, since ambulances do not carry blood and instead administer crystalloid. Unlike HBOCs, crystalloid fluids possess no oxygen carrying capacities and are used to simply maintain blood volume in trauma patients. However, ethicists suggested the conditions allowing the waiver of informed consent was then violated once the patients reached the ED because the PolyHeme subjects failed to receive blood and instead continued to receive the test solution. ${ }^{46}$ They contended that since blood is readily available in the ED and is a proven therapy, the use of PolyHeme in the ED was unethical because patients were not given blood, but instead received an experimental treatment.

The need for an effective study design that both follows the scientific process and complies with community ethical standards is essential for the continued evaluation of any HBOC product. Society must determine how much risk the population will accept to save lives in the short term and to reduce mortality in the future. Inherent in any research endeavor is the problem of risk, and communities must weigh the possible benefits of the study against its possible risks. However, these communities must be fully educated about the study and investigators must make every effort to inform the communities in which the study will be carried out about the trial. 


\section{Meta-analysis}

A recent meta-analysis published by Natanson et al. examined the overall mortality rates of the three HBOCs we reviewed, as well as a few other HBOCs, and all were combined as a product class. ${ }^{47}$ The study found that patients treated with an HBOC had a $30 \%$ increased risk of mortality and a 2.7-fold increase for myocardial infarction. Further analyses indicate that these increased risks are consistent across patient population or specific product type. Because of these findings, Natanson et al. argue for preclinical animal studies of any existing or developing HBOCs in order to test for known toxicities. We suggest such studies must have a priori set endpoints and should be conducted by independent groups with FDA regulatory oversight.

The study also criticizes the lack of timely data put forth by the companies and the lack of published studies. Both Hemopure and Polyheme published studies only several years after the completion of their trials. Additionally, unpublished studies render a thorough IRB review of trials difficult. Natanson et al. argue for the timely and complete disclosure of data to the scientific community to avoid exposing the public to unnecessary risks.

Biopure responded to the Natanson et al. meta-analysis by claiming the authors made fundamental errors when analyzing the data and claimed the meta-analysis was inappropriately applied. ${ }^{48}$ Biopure also claimed there were errors in the authors' calculations, and also stated that the products chosen for inclusion in the meta-analysis were inappropriately grouped and generalized.

\section{New HBOCs in Development}

Other companies, such as HemoBioTech, Sangart, and Oxygenix are currently working to develop HBOCs, but have not reported data from U.S. clinical trials. HemoTech was developed by HemoBioTech and derived from bovine hemoglobin. It underwent foreign pre-clinical and clinical testing in the late 1980s and early 1990s. ${ }^{49}$ At the time of writing, HemoBioTech, in conjunction with Paragon Biomedical, is pursuing clinical trials in India. Sangart produces Hemospan, which is derived from human hemoglobin that has been chemically modified by attaching polyethylene glycol polymers its surface. ${ }^{50}$ Sangart is conducting Phase II trials in the U.S. and Phase III trials in Europe. Using a different approach to modifying hemoglobin, the U.S. Navy began researching liposome-encapsulated hemoglobin, or neo red cells. This unique oxygen carrier is being developed by Oxygenix, the company that produces Oxy-0301, and is still in the experimental phase. ${ }^{51}$

\section{SUMMARY}

Based on the results of clinical results, the efforts of Baxter, Northfield and Biopure to develop a safe and effective HBOC have not met with success to date. Tables 2-4 demonstrate both the potential and the limitations of the HBOCs reviewed. In some studies, the HBOCs did significantly decrease or eliminate the need for PRBC transfusions. Alarmingly, they also resulted in greater incidences of adverse side effects including pulmonary hypertension and cardiac depression. Our analysis and the conclusions of these studies suggest that the risks of using HBOCs currently exceed the benefits. It does not seem likely that any of these products will become successful in their present formulation until these unwanted effects are resolved. Despite many setbacks in the development of its product, Biopure continues to work towards FDA approval.

The quest for the Holy Grail of blood substitutes remains unfulfilled. To succeed, investigators must overcome scientific barriers, as well as federal regulation and social apprehension. However, if such a product can be developed, it will dramatically change both surgical and critical care medicine.

\section{REFERENCES}

1. McCullough J. Progress toward a pathogen-free blood supply. Clin Infect Dis. 2003;37:88-95.

2. Ross S, Jeter E. Emergency surgery, trauma, and massive transfusion. In: Petz LD, Kleinmann S, Swisher SN, Spence RK, Strauss RG, eds. Clinical Practice of Transfusion Medicine. 3rd ed. New York: Churchill Livingstone; 1996. p.563-79.
3. Dunne JR, Malone DL, Tracy JK, Napolitano LM. Allogeneic blood transfusion in the first 24 hours after trauma is associated with increased systemic inflammatory response system (SIRS) and death. Surgical Infections. 2004;5:395-404

4. Moore FA, Moore EE, Sauaia A. Blood transfusion: An independent risk factor for post injury multiple organ failure. Arch Surg. 1997;132:62025 . 
5. Thomas TG. The intravenous injection of milk as a substitute for the transfusion of blood. NY State J Med. 1878;47:449-65.

6. Amberson WR, Mulder AG, Steggerda FR, Flexner J, Pankratz DS Mammalian life without red blood corpuscles. Science. 1933;78:106-7.

7. Amberson WR, Jennings JJ, Rhode CM. Clinical experience with hemoglobin-saline solutions. J Appl Physiol. 1949;1:469-89.

8. Winslow RM. The results of 62 large-volume hemoglobin infusions in man. Hemoglobin-Based Red Cell Substitutes. Baltimore and London: Johns Hopkins University Press 1992:177-8.

9. Bunn H, Jandl J. The renal handling of hemoglobin. Transactions of the Association of American Physicians. 1968;81:147-52.

10. Winslow RM. $\alpha \alpha$-Crosslinked hemoglobin. In: Winslow RM, editor. Blood Substitutes. London: Academic Press 2006. p.386-98.

11. Winslow RM. Hemoglobin modification. In: Winslow RM, editor. Blood Substitutes. London: Academic Press 2006. p.341-53.

12. Bonsen P, Laver M, Morris K, inventors; Alza Corporation, assignee. Novel polymerized, cross-linked, stroma-free hemoglobin. United States. 1975.

13. Tam S, Blumenstein J, Wong J. Soluble dextran-hemoglobin complex as a potential blood substitute (plasma expander/oxygen binding/covalent coupling). Proc Natl Acad Sci USA. 1976;73:2128-31.

14. Humphries RG, Killingback PG, Mann J, Sempik J, Wilson J. Exchange transfusion with dextran-hemoglobin, hemoglobin and dextran solutions in anaesthetized cats. Br J Pharmacol. 1980.74:266.

15. Lamy ML, Daily EK, Brichant JF, Larbuisson RP, Demeyere RJ, Vandermeersch EA, et al. Randomized trial of Diaspirin Cross-Linked hemoglobin solution as an alternative to blood transfusion after cardiac surgery. Anesthesiology. 2000;92:646-56.

16. Nolte D, Steinhauser P, Pickelmann S, Berger S, Härtl R, Messmer K. Effects of Diaspirin-Cross-Linked hemoglobin (DCLHb) on local tissue oxygen tension in striated skin muscle: An efficacy study in the hamster. J Lab Clin Med. 1997;138:328-38.

17. Northfield. Potential battle field use [Online]. 2006. [cited 2007 April 26] Available from: http://www.northfieldlabs.com/us_army.html

18. Handrigan MT, Bentley TB, Oliver JD, Tabaku L, Buge J, Atkins J. Choice of fluid influences outcome in prolonged hypotensive resuscitation after hemorrhage in awake rats. Shock. 2005;23:337-43.

19. Dubick MA, Sondeen JL, Prince MD, James AG, Nelson JJ, Hernandez EL. Hypotensive resuscitation with Hextend, Hespan or PolyHeme in a swine hemorrhage model. Shock. 2004;21 (Suppl 2):42. (abstract)

20. Johnson JL, Moore EE, Offner PJ, Haenel JB, Hides GA, Tamura DY. Resuscitation of the injured patient with polymerized stroma-free hemoglobin does not produce systemic or pulmonary hypertension. Am J Surg. 1998;176:612-7.

21. Gould SA, Sehgal LR, Sehgal HL, Moss GS. The development of hemoglobin solutions as red cell substitutes: Hemoglobin solutions. Transfusion Science. 1995;16:5-17.

22. Thompson A, McGarry AE, Valeri R, Liberthal W. Stroma-free hemoglobin increases blood pressure and GFR in the hypotensive rate: role of nitric oxide. J Appl Physiol. 1994;77:2348-54.
23. Gould SA, Moore EE, Hoyt DB, Burch JM, Haenel J, Garcia J, et al. The first randomized trial of human polymerized hemoglobin as a blood substitute in acute trauma and emergent surgery. Journal of the American College of Surgeons. 1998;187:113-20.

24. Northfield. Northfield Laboratories reports preliminary top-line data in pivotal Phase III trauma study [press release]. [Online] Evanston, IL: Business Wire; [updated 2006 December 16; cited 2007 April 26]. Available from: http://phx.corporate-ir.net/phoenix.zhtml?c=91374\&p =irolnewsArticle $\&$ ID=943580\&highlight $=$

25. Northfield. Northfield Laboratories reports results of pivotal Phase III trauma study [press release]. [Online] Evanston, IL: Business Wire; [updated 2007 May 23; cited 2007 June 14]. Available from: http://phx.corporate-ir.net/phoenix.zhtml?c=91374\&p=irolnewsArticle\&ID=1005951\&highlight=

26. Rentko VT, Pearce LB, Moon-Massat PF, Gawryl MS. Hemopure (HBOC-201, Hemoglobin Glutamer-250 (Bovine)): preclinical studies. In: Winslow RM, editor. Blood Substitutes. London: Academic Press 2006. p.424-36.

27. Pearce BL, Gawryl MS, Rentko VT. HBOC-201(Hemoglobin Glutamer-250 (Bovine),Hemopure): Clinical Studies. In: Winslow, RM, editor. Blood Substitutes. London: Academic Press; 2006. p.437-50.

28. Biopure Corporation. Biopure announces 2007 third quarter financial results [press release]. [Online]. Cambridge, MA: PRNewswireFirstCall; [updated 2007 August 23; cited 2008 May 7]. Available from: http://www.bio-medicine.org/medicine-technology-1/biopureannounces-2007-third-quarter-financial-results-129-1/

29. Saxena R, Wijnhoud A, Carton H, Hacke W, Kaste M, Przybelski R, et al. Controlled safety study of a hemoglobin-based oxygen carrier, DCLHb, in acute ischemic stroke. Stroke. 1999;30:993-96. Stroke. 1999;30:993-96

30. Schubert A, Przybelski RJ, Eidt JF, Lasky LC, Marks KE, Karafa M, et al. Diaspirin-Crosslinked hemoglobin reduces blood transfusion in noncardiac surgery: A multicenter, randomized controlled, doubleblinded trial. Anesth Analg. 2003;7:323-32.

31. University of Illinois at Chicago. U.S. trauma study design [Online]. 1998 [cited 2007 April 27]; Available from: http://web.archive.org/ web/19990302030029/dclhb.er.uic.edu/ustrauma.htm

32. Sloan EP, Koenigsberg M, Gens D, Cipolie M, Runge J, Mallory MN, et al. Diaspirin cross-linked hemoglobin (DCLHb) in the treatment of severe traumatic hemorrhage shock: A randomized controlled efficacy trial. JAMA. 1999;282(19):1857-64.

33. Baxter Healthcare Corporation. Baxter ends U.S. trauma study of HemAssist (DCLHb); European trauma and U.S. surgery trials continue on track [press release]. [Online]. Deerfield, IL: PRNewswire; [updated, 1988 March 31; cited 2007 April 27]. Available from: http://web.archive. org/web/19981205122026/dclhb.er.uic.edu/press_release.htm

34. Kerner T, Ahlers O, Veit S, Riou B, Saunders M, Pison U. DCLHb for trauma patients with severe hemorrhagic shock: The European "onscene" multicenter study. Intensive Care Med. 2003;29:347-49.

35. Gould SA, Moore EE, Hoyt DB, Ness PM, Norris EJ, Carson JL, et al. The life-sustaining capacity of human polymerized hemoglobin when red cells might be unavailable. Journal of the American College of Surgeons. 2002;195:445-52 
36. Kasper SM, Walter M, Grüne F, Bischoff A, Erasmi H, Buzello W. Effects of hemoglobin-based oxygen carrier (HBOC-201) on hemodynamics and oxygen transport in patients undergoing preoperative hemodilution for elective abdominal aortic surgery. Anesth Analg. 1996;83:912-27.

37. Bloomfield EL, Rady MY, Esfandiari S. A prospective trial of diaspirincross linked hemoglobin solution in patients after elective repair of abdominal aortic aneurysm. Mil Med. 2004;169:546-50.

38. LaMuraglia G, O'Hara PJ, Baker WH, Naslund TC, Norris EJ, Li J, et al. The reduction of the allogenic transfusion requirement in aortic surgery with a hemoglobin-based solution. J Vasc Surg. 2000;31:299-308.

39. Levy JH, Goodnough LT, Greilich PE, Parr GS, Stewart RW, Gratz I, et al. Polymerized bovine hemoglobin solution as a replacement for allogeneic red blood cell transfusion after cardiac surgery: Results of a randomized, double-blind trial. J Thorac Cardiovas Surg. 2002;124:3542 .

40. Sprung J, Kindscher JD, Waher JA, Levy JH, Monk TG, Moritz MW, et al. The use of bovine hemoglobin glutamer-250 (Hemopure) in surgical patients: Results of a multicenter, randomized, single-blinded trial. Anesth Analg. 2002;94:799-808.

41. Biopure Corporation. FDA panel recommends Navy's proposed 'RESUS' Phase IIb/III trauma trial not proceed as designed; suggests phase II study [press release]. [Online]. Cambridge, MA: PRNewswireFirstCall; [updated 2006 December 15; cited 2007 April 26]. Available from: http://www.corporateir.net/ireye/ir_site.zhtml?ticker=bpur\&scri $\mathrm{pt}=419$ \&layout $=0$ \&item_id $=942537$

42. Jahr JS, Mackenzie C, Pearce LB, Pitman A, Greenburg AG. HBOC-201 as an Alternative to Blood Transfusion: Efficacy and Safety Evaluation in a Multicenter Phase III Trial in Elective Orthopedic Surgery. J Trauma. 2008:64:1484-97.

43. Orfinger B. South Africa approves first blood substitute. [Online] 2001. [cited 2007 April 25]. Available from: http://www.redcross.org/news/ bm/intl/010419sub.html
44. [Food and Drug Administration. Part 50- Protection of human subjects Subpart B- informed consent of human subjects Sec 50.24 Exception from informed consent requirements for emergency research [Online]. 1996 [cited 2007 April 26] Available from: http://www.accessdata.fda. gov/scripts/cdrh/cfdocs/cfcfr/CFRSearch.cfm?fr $=50.2$

45. Guterman L. Guinea pigs in the ER: Researchers debate the ethics and logistics of performing emergency research without patients' consent. The Chronicle of Higher Education. 2006;52:A14-8.

46. Kipnis K, King NP, Nelson RM. An open letter to IRBs considering Northfield Laboratories' PolyHeme trial. The American Journal of Bioethics. 2006;6:18-21.

47. Natanson C, Kern SJ, Lurie P, Banks SM, Wolfe SM. Cell-Free Hemoglobin-Based Blood Substitutes and Risk of Myocardial Infarction and Death: A Meta-analysis. JAMA. 2008;299:2304-12.

48. Biopure. Scientific Commentary on the Natanson et al. Meta-analysis [Online] 2008 [cited 2008 October 16]; Available from: http://www. biopure.com/jamacomments.php

49. HemoBioTech. Our product- clinical testing. [Online] 2006 [cited 2008 May 6]; Available from: http://hemobiotech.com/product/ clinicalresearch.php

50 Sangart. Hemospan: Product information. [Online] 2007. [cited 2008 May 6]. Available from: http://www.sangart.com/hemospan/productinfo.php

51 Oxygenix. Oxy-0301- oxygen carrier. [Online] 2006. [cited 2008 May 6]. Available from: http://www.oxy-genix.com/english/kenkyu/jinko. html 